\title{
Fixation of delayed distal radial fracture involving metaphyseal diaphyseal junction in adolescents: a comparative study of crossed Kirschner-wiring and non-bridging external fixator
}

\author{
Jin $\mathrm{Li}^{1}$, Saroj Rai ${ }^{2}$, Xin Tang ${ }^{1}$, Renhao Ze ${ }^{1}$, Ruikang Liu ${ }^{3}$ and Pan Hong ${ }^{1 *}$ (D)
}

\begin{abstract}
Background: Conservative treatment remains the preferred choice for distal radius fracture in children. However, loss of reduction is problematic, especially in an older child. Crossed Kirschner-wires is widely used to treat distal radius fracture in adolescents. This study aimed to compare the application of crossed Kirschner-wiring (KW) and non-bridging external fixator (EF) for the treatment of delayed distal radial fracture involving metaphyseal diaphyseal junction (MDJ) in adolescents.

Methods: Between January 2012 to January 2017, 146 (male $=101$, female $=45)$ patients in EF group and 117 ( male $=76$, female $=41$ ) in KW group, were reviewed retrospectively. Preoperative data were collected from the hospital database, and postoperative clinical outcomes data were collected during the follow-up visits. We used SPSS for data analysis.

Results: There existed no significant difference between EF and KW regarding sex, body weight, fracture side, duration from injury to surgery. The duration of surgery was significantly shorter in EF (30.5 $\pm 6.1 \mathrm{~min})$ than the KW group ( $44.6 \pm 9.4 \mathrm{~min}), P<0.001$. The number of intraoperative $X$-ray images was significantly lower in $\mathrm{EF}(6.5 \pm 1.1)$ than KW (11.8 \pm 2.3$), P<0.001$. The incidence of tendon irritation is significantly higher in the KW (19.7\%) than the EF group (0\%), $P<0.001$. The residual angulation on the AP view was higher in KW (3.8 \pm 2.3 , degrees) than the EF group ( $2.5 \pm 1.6$, degrees), $P<0.001$. The volar tilting is better in $\mathrm{EF}(6.6 \pm 1.1$, degrees) than the KW group $(1.0 \pm 1.5$, degrees), $P<0.001$. However, the functional outcomes of the wrist showed no significant difference between $E F$ and $\mathrm{KW}$ group, $P=0.086$.

Conclusion: The EF was superior to KW in the treatment of radial MDJ fractures in adolescents. The EF displayed shorter duration of surgery, less tendon irritation, and better radiographic outcomes than the KW. However, the cost-effect analysis remains to be investigated, because the EF is more expensive than KW.
\end{abstract}

Keywords: Distal radius fracture, Metaphyseal diaphyseal junction, External fixator, Crossed Kirschner-wiring

* Correspondence: hongpan2013@foxmail.com

'Department of Orthopaedic Surgery, Union Hospital, Tongji Medical College, Huazhong University of Science and Technology, Wuhan 430022, China

Full list of author information is available at the end of the article

C C The Author(s). 2020 Open Access This article is licensed under a Creative Commons Attribution 4.0 International License, which permits use, sharing, adaptation, distribution and reproduction in any medium or format, as long as you give appropriate credit to the original author(s) and the source, provide a link to the Creative Commons licence, and indicate if changes were made. The images or other third party material in this article are included in the article's Creative Commons licence, unless indicated otherwise in a credit line to the material. If material is not included in the article's Creative Commons licence and your intended use is not permitted by statutory regulation or exceeds the permitted use, you will need to obtain permission directly from the copyright holder. To view a copy of this licence, visit http://creativecommons.org/licenses/by/4.0/. The Creative Commons Public Domain Dedication waiver (http://creativecommons.org/publicdomain/zero/1.0/) applies to the data made available in this article, unless otherwise stated in a credit line to the data. 


\section{Background}

Distal radius fracture is a common injury in children and adolescents [1]. The nonoperative method of treatment remains the primary choice for the pediatric population, especially in younger children [2, 3]. Adolescents with similar injury patterns of the distal radius as in adults display a unique fracture, and the vulnerable zone is usually the metaphyseal diaphyseal junction (MDJ) [4]. We defined the MDJ as the distal third of radius subtract the square over the radial physis (Fig. 1), and it is a reproducible basis for evaluation.

Because of limited remodeling potential and higher demand for wrist function in adolescents, surgical intervention was advocated [5]. The surgical intervention includes plates [6], elastic stable intramedullary nail (ESIN) [7, 8], and Kirschner wire (KW) [4, 9]. It is indicated if (1) the fracture is unstable or difficult to reduce, (2) loss of fracture reduction at follow-up radiographs: more than 15 degrees on sagittal plane, more than 5 degrees on frontal plane, and (3) impending compartment syndrome with the cast.

Surgery is meant for better stability and accurate fixation. However, all these techniques have various disadvantages of being technically demanding, and plating requires a large incision and is usually unacceptable to the patients and parents.

As a tertiary medical center, the majority of patients at the out-patient visit were transferred from local hospitals. Delayed presentation of displaced distal radius fractures in adolescents was common as manual reduction and casting or splinting were usually tried for most of the patients before arrival at our hospital. We considered a delayed presentation if the patients arrive hospital after $72 \mathrm{~h}$. Antegrade ESIN was quite challenging and is not a preferred option in our hospital. Before the introduction of an external fixator (EF), KW was our preferred choice. A simple technique using EF to stabilize MDJ fractures was introduced in our institute since 2012. It is a simple and minimally invasive surgical procedure and has a short learning curve.

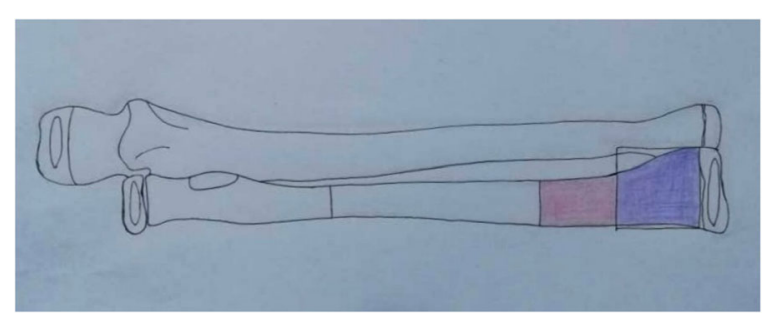

Fig. 1 Schematic illustration of the fracture in this study (anteroposterior view). The blue square is a square area whose side has the same length of the distal physis of the radius; We defined the MDJ (red area) as the distal third of radius subtract the blue square
This retrospective study aims to compare the outcomes and complications of EF and crossed KW for the treatment of delayed MDJ fractures in adolescents.

\section{Methods \\ Study population}

All patients in this study were treated surgically in the Department of Orthopaedic Surgery, Wuhan Union Hospital, Tongji Medical College, Huazhong University of Science and Technology, between January 2012 and January 2017. Patients were categorized into the EF group and the KW group according to the surgical procedures.

Patients in this study were required to fit following criteria: (1) 10-14 year-old; (2) complete fracture of the distal radius, with or without ulna fracture; (3) failed trials of nonoperative treatment; (4) two-part fracture without comminution or with slight comminution; (5) injury to surgery more than 3 days; (6) MDJ fractures with open visible physis on the radiographs.

Exclusion criteria were as follows: (1) severely comminuted fractures; (2) radial styloid fractures; (3) fractures associated with neurovascular injuries; (4) pathological fractures or open fractures; (4) duration from injury to surgery over 14 days.

Baseline information including sex, age, operative side, absence/presence of ulnar fracture, duration from injury to surgery, duration of operation, number of intraoperative X-ray images, duration from surgery to hardware removal, rotation of forearm, were reviewed retrospectively from the hospital database. The functional outcome of the wrist was measured at the follow-up visit, using the Disabilities of the Arm, Shoulder and Hand (DASH) Score [10]. Fractures union was evaluated by radiographs, including wrist joint and full-length forearm, at every outpatient visit.

\section{Surgical technique}

The surgery was performed under brachial plexus block (BPB) or general anesthesia (GA), without the usage of the pneumatic tourniquet. The forearm was placed on a radiolucent table, and the surgery was performed under fluoroscopic guidance.

The external fixator application was performed as follows. The fracture was manually reduced until the satisfactory alignment was achieved, and two Schanz pins (Tianjin Xinzhong Medical Devices Co. Ltd., Tianjin City, China) were placed in the distal fracture fragment. The insertion point of the distal-most screw should be at least $5-10 \mathrm{~mm}$ proximal to the physeal line. Then, the other two screws were placed in the proximal fracture fragment radially, and the screws were connected with proper clamps and rods. The fracture alignment was confirmed with fluoroscopy on anterior-posterior (AP) 
and lateral view. Sometimes, if the manual reduction was difficult, a K-wire was utilized as a lever to facilitate the reduction. Usually, the ulna was not fixated (Fig. 2).

Crossed K-wire fixation was performed as follows. Under fluoroscopy guidance, the fracture was manually reduced, and a pair of K-wires were inserted in a crossed fashion to fixate the fracture. If manual reduction failed, a pin was used as a lever to facilitate reduction (See Fig. 3 and Fig. 4).

After surgery, all patients were immobilized in short or long arm cast for 3-4 weeks. The EF was usually removed at 4-8 weeks at the out-patient department, as per the clinical and radiographic evidence of fracture union. The KWs were removed similarly as EF. After the removal of hardware, a short-arm brace was used for the patient for additional 3-4 weeks.

\section{Follow-up}

Patients were followed-up for at least 12 months after index surgery. Data, including the time of hardware removal, range of forearm rotation, range of wrist motion,
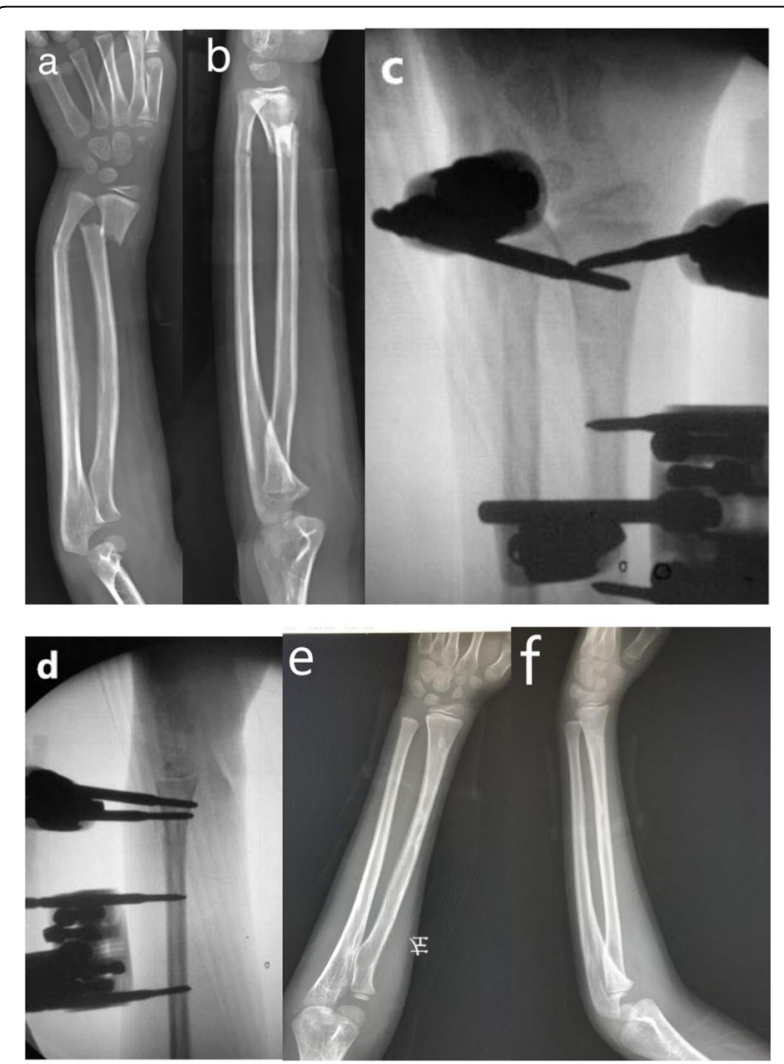

Fig. 2 11-year-old boy with left distal radius-ulna fracture treated with external fixator. a AP view of forearm before surgery. $\mathbf{b}$ Lateral view of forearm before surgery. c AP view of forearm after surgery. $\mathbf{d}$ Lateral view of forearm after surgery. e AP view of forearm at 12th month follow-up after surgery. f. Lateral view of forearm at 12th month follow-up after surgery fracture re-displacement and postoperative complications, were collected and recorded.

\section{Statistical analysis}

SPSS statistical package program (SPSS 19.0 version; SPSS Inc., Chicago, Illinois, USA) was used for statistical analysis. Data were presented as mean \pm SD (range), median (range), or $\mathrm{n}(\%) \cdot \mathrm{x}^{2}$-test (categorical data) or Student's t-test (continuous data) was used to compare the results from two groups. And a $P$-value of $<.05$ was considered significantly different.

\section{Results}

In all, 146 patients (male 101, female 45) in the EF and 117 patients (male 76, female 41) in the KW group were included, and all the patients were followed up for more than 12 months. As shown in Table 1, there existed no statistically significant differences between the two groups regarding sex, body weight, fracture side, duration from injury to surgery. The duration of surgery was significantly shorter in the EF $(30.5 \pm 6.1 \mathrm{~min})$ than the KW group $(44.6 \pm 9.4 \mathrm{~min})(P<0.001)$. The number of intraoperative $\mathrm{X}$-ray images was significantly lower in the EF $(6.5 \pm 1.1)$ than the KW $(11.8 \pm 2.3),(P<0.001)$.

As shown in Table 2, there existed no statistically significant differences between the EF and KW group regarding the time from surgery to implant removal, pin tract infection, loss of forearm rotation, range of wrist motion. The incidence of tendon irritation is significantly higher in the KW (19.7\%) than the EF group (0\%) $(P<0.001)$. The residual angulation on the AP view was higher in the KW $(3.8 \pm 2.3$ degrees $)$ than the EF group ( $2.5 \pm 1.6$, degrees), $P<0.001$. The volar tilting is better in the EF (6.6 \pm 1.1 , degrees) than the KW group $(1.0 \pm$ 1.5 degrees $)(P<0.001)$.

As shown in Table 3, 30 patients (male 20, female 10) in the EF and 23 patients (male 15, female 8 ) in the KW group presented with both-bone fractures of the forearm. There existed no significant difference between the two groups regarding sex, body weight, fracture side, duration from injury to surgery. The duration of surgery was significantly shorter in the EF $(31.9 \pm 5.9, \mathrm{~min})$ than the KW group $(44.2 \pm 9.6$, min $)(P<0.001)$. The number of intraoperative $\mathrm{X}$-ray images was significantly lower in the EF $(6.6 \pm 1.1)$ than KW $(12.4 \pm 2.4)(P<0.001)$.

As shown in Table 4, for patients with both-bone fractures of the forearm, there existed no significant difference between EF and KW group regarding the time from surgery to implant removal, pin tract infection, loss of forearm rotation, range of wrist motion. The incidence of tendon irritation is significantly higher in the KW group (26.1\%) than the EF group (0\%), $P<0.001$. The residual angulation on the AP view was higher in KW $(4.2 \pm 2.5$, degrees) than the EF group $(2.7 \pm 1.4$, 

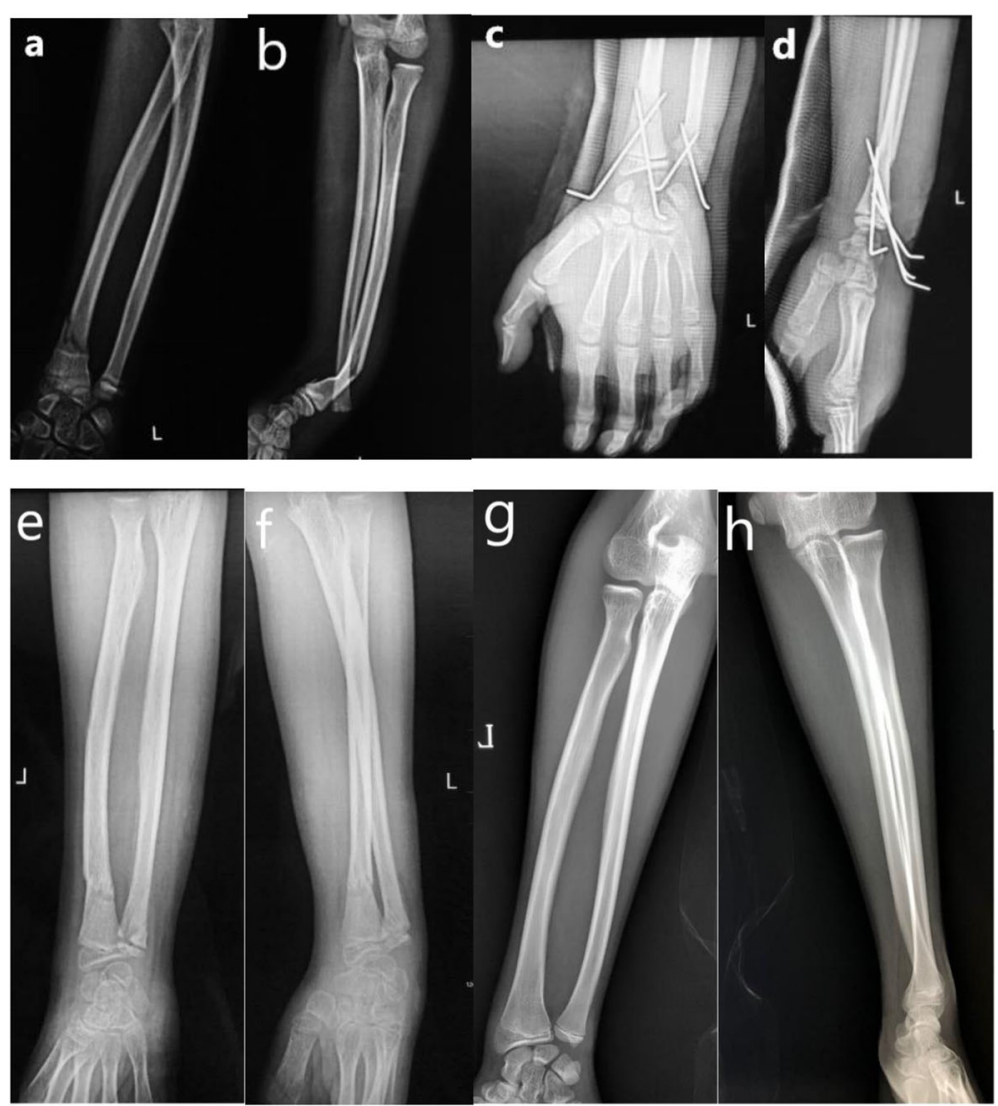

Fig. 3 13-year-old boy with left distal radius-ulna fracture treated with crossed KW fixation. a AP view of forearm before surgery. $\mathbf{b}$ Lateral view of forearm before surgery. c AP view of wrist joint after surgery. $\mathbf{d}$ Lateral view of wrist joint after surgery. e AP view of forearm after Kirschner wire removal. $\mathbf{f}$ Lateral view of forearm after Kirschner wire removal. $\mathbf{g}$ AP view of forearm at 18th month follow-up. $\mathbf{h}$ Lateral view of forearm at 18 th month follow-up

degrees), $P=0.018$. The volar tilting is better in the EF $(6.5 \pm 1.1$, degrees) than the KW group $(1.3 \pm 1.3$, degrees) $(P<0.001)$.

As shown in Table 5, 116 patients (male 81, female 35 ) in the EF and 94 patients (male 61, female 33) in the KW group presented with isolated radial MDJ fractures. There existed no significant difference between the two groups regarding sex, body weight, fracture side, duration from injury to surgery. The duration of surgery was significantly shorter in the EF $(30.2 \pm 6.2$, min) than the KW group $(44.7 \pm 9.4$, min $)(P<0.001)$. The number of intraoperative $\mathrm{X}$-ray images was significantly lower in the EF $(6.5 \pm 1.1)$ than KW $(11.6 \pm 2.2)(P<0.001)$.

As shown in Table 6, for patients with both-bone fractures of the forearm, there existed no significant differences between the EF and KW group regarding the time from surgery to implant removal, pin tract infection, loss of forearm rotation, range of wrist motion. The incidence of tendon irritation is significantly higher in the KW group $(18.1 \%)$ than the EF group $(0 \%)(P<0.001)$. The residual angulation on the AP view was higher in the KW (3.6 \pm 2.2 degrees) than the EF group $(2.5 \pm 1.7$ degrees $)(P<0.001)$. The volar tilting is better in the EF (6.7 \pm 1.1 degrees) than the KW group $(0.9 \pm 1.5$ degrees $)$ $(P<0.001)$.

No patient in the EF and KW groups required reoperation. Five patients in the EF and 4 patients in the KW suffered refracture after hardware removal. Three patients in the EF resulted from an accidental fall onto the ground, and 2 resulted from accidental bumping into the hard surface. Four patients in the KW group results from accidental fall.

\section{Discussion}

The most important finding of our study was that radiograph showed better volar tilting and less angulation in the EF than KW. Besides, EF displayed shorter duration of surgery, less tendon irritation than the KW. Therefore, the EF was superior to KW in the treatment of delayed MDJ fractures in adolescents.

Some authors advocated the use of EF in the shaft of radius fractures in children [11, 12], and some reported the use of non-bridging EF for the distal radius fractures in adults [13-16]. Even recently, Korobeinikov et al. 

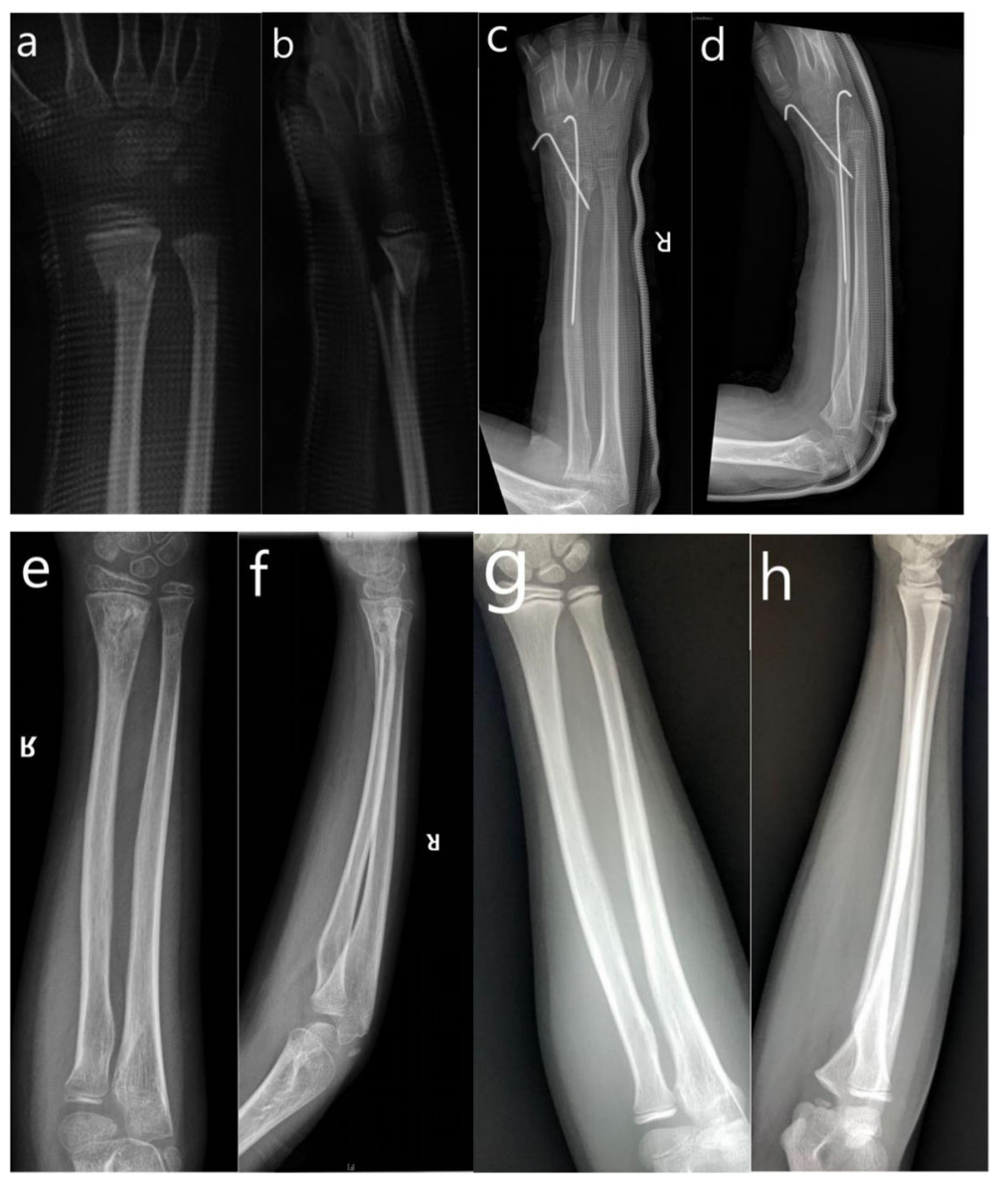

Fig. 4 11-year-old boy of right distal radius-ulna fracture treated with crossed KW fixation. a. AP view of wrist joint before surgery. b. Lateral view of wrist joint before surgery. c. AP view of full-length forearm after surgery. $\mathbf{d}$. Lateral view of full-length forearm after surgery. e. AP view of forearm at 9th month follow-up. f. Lateral view of forearm at 9th month follow-up. $\mathbf{g}$. AP view of forearm at 15th month follow-up. $\mathbf{h}$. Lateral view of forearm at 15 th month follow-up

Table 1 Demographic and clinical parameters of children with radial MDJ fractures in EF and KW group

\begin{tabular}{llll}
\hline Parameters & EF $(n=146)$ & $\mathrm{KW}(n=117)$ & $P$ Value \\
\hline Age, years & $12.1 \pm 1.4$ & $11.9 \pm 1.5$ & 0.322 \\
Sex, male/female & $101 / 45$ & $76 / 41$ & 0.469 \\
Body Weight $(\mathrm{kg})$ & $33.6 \pm 4.2$ & $33.9 \pm 4.9$ & 0.583 \\
Fracture side, L/R & $84 / 62$ & $74 / 43$ & 0.347 \\
Combined ulnar fracture (\%) & 20.5 & 19.7 & 0.858 \\
Duration of surgery, min & $30.5 \pm 6.1$ & $44.6 \pm 9.4$ & $<0.001^{*}$ \\
Images taken during the operation & $6.5 \pm 1.1$ & $11.8 \pm 2.3$ & $<0.001^{*}$ \\
From injury to surgery (d) & $5.1 \pm 1.4$ & $5.3 \pm 1.4$ & 0.266 \\
\hline
\end{tabular}

Data shown as mean $\pm \mathrm{SD}$ or $\mathrm{N}(\%)$ ${ }^{*}<0.01$
Table 2 Follow-up data for children with radial MDJ fractures in EF and KW group

\begin{tabular}{llll}
\hline Parameter & EF $(n=146)$ & KW $(n=117)$ & P Value \\
\hline Hardware removal, weeks & $6.5 \pm 1.1$ & $6.6 \pm 1.1$ & 0.492 \\
Pin tract infection (\%) & 10.3 & 10.3 & 0.997 \\
Tendon Irritation (\%) & 0 & 19.7 & $<0.001^{*}$ \\
Forearm pronation ( $\left.{ }^{\circ}\right)$ & $87.2 \pm 1.6$ & $87.2 \pm 1.6$ & 0.932 \\
Forearm supination $\left(^{\circ}\right)$ & $87.6 \pm 1.7$ & $87.7 \pm 1.7$ & 0.596 \\
DASH score & $12.3 \pm 1.7$ & $12.7 \pm 1.7$ & 0.086 \\
Angulation $\left(^{\circ}\right)$ & $2.5 \pm 1.6$ & $3.8 \pm 2.3$ & $<0.001^{*}$ \\
Volar tilt( $\left(^{\circ}\right)$ & $6.6 \pm 1.1$ & $1.0 \pm 1.5$ & $<0.001^{*}$ \\
\hline
\end{tabular}

Data shown as mean \pm SD or $\mathrm{N}(\%)$

Angulation $=$ angulation on frontal plane

${ }^{*}<0.01$ 
Table 3 Demographic and clinical parameters of children with distal forearm both-bone fractures

\begin{tabular}{llll}
\hline Parameters & $\mathrm{EF}(n=30)$ & $\mathrm{KW}(n=23)$ & P Value \\
\hline Age, years & $11.7 \pm 1.3$ & $12.2 \pm 1.6$ & 0.187 \\
Sex, male/female & $20 / 10$ & $15 / 8$ & 0.907 \\
Body Weight (kg) & $33.1 \pm 3.9$ & $35.1 \pm 4.8$ & 0.111 \\
Fracture side, L/R & $20 / 10$ & $14 / 9$ & 0.644 \\
Duration of surgery, min & $31.9 \pm 5.9$ & $44.2 \pm 9.6$ & $<0.001^{*}$ \\
Images taken during the operation & $6.6 \pm 1.1$ & $12.4 \pm 2.4$ & $<0.001^{*}$ \\
From injury to surgery (d) & $5.6 \pm 1.3$ & $5.3 \pm 1.2$ & 0.460
\end{tabular}

EF External fixator, $K W$ Kirschner wire

Data shown as mean $\pm \mathrm{SD}$ or $\mathrm{N}(\%)$

$*<0.01$

reported the utilization of the Ilizarov frame for the distal radius fracture in children, with satisfactory clinical outcomes [17]. However, none of the previous studies reported the utilization of simple EF for the treatment of MDJ fractures in children. Generally, there are three types of EF available for adults [18]. These include F-wrist, Hoffman II Compact, and Pennig Dynamic Wrist Fixator, but such devices are not available in our hospital. Hybrid EF is readily available and relatively easy to assemble, which utilizes the different sizes of Schanz screws and clamps. Though it looks bulky, patient compliance is good.

Displaced distal radial fractures (DDRF) in children and adolescents usually require intervention that varies from simple manual reduction followed by well-molded casting to KW fixation and even plating [19]. In children with DDRF, the re-operation rate following manipulation under anesthesia alone ranges from 14 to $91 \%$ [20]. The limited remodeling potential and high demand for wrist function among teenagers require an acceptable reduction and adequate stabilization. Most authors prefer additional $\mathrm{KW}$ fixation over casting alone [21, 22]. Lieber et al. even reported the use of transepiphyseal intramedullary KW for

Table 4 Follow-up data for children with distal forearm both bone fractures in EF and KW group

\begin{tabular}{llll}
\hline Parameter & EF $(n=30)$ & KW $(n=23)$ & P Value \\
\hline Hardware removal, weeks & $6.4 \pm 1.1$ & $6.6 \pm 0.9$ & 0.463 \\
Pin tract infection (\%) & 10.0 & 4.3 & 0.462 \\
Tendon Irritation (\%) & 0 & 26.1 & $<0.001^{*}$ \\
Forearm pronation ( $\left.{ }^{\circ}\right)$ & $87.4 \pm 1.5$ & $87.3 \pm 1.5$ & 0.680 \\
Forearm supination $\left(^{\circ}\right)$ & $87.5 \pm 1.6$ & $86.7 \pm 1.6$ & 0.092 \\
DASH score & $12.4 \pm 1.5$ & $12.7 \pm 1.4$ & 0.517 \\
Angulation $\left(^{\circ}\right)$ & $2.7 \pm 1.4$ & $4.2 \pm 2.5$ & 0.018 \\
Volar tilt $\left(^{\circ}\right)$ & $6.5 \pm 1.1$ & $1.3 \pm 1.3$ & $<0.001^{*}$ \\
\hline
\end{tabular}

Data shown as mean \pm SD or $\mathrm{N}(\%)$

Angulation $=$ angulation on frontal plane

$* 0.01$
Table 5 Demographic and clinical parameters of children with isolated radial MDJ fractures in EF and KW group

\begin{tabular}{llll}
\hline Parameters & EF $(n=116)$ & $\mathrm{KW}(n=94)$ & P Value \\
\hline Age, years & $12.2 \pm 1.4$ & $11.9 \pm 1.5$ & 0.074 \\
Sex, male/female & $81 / 35$ & $61 / 33$ & 0.441 \\
Body Weight $(\mathrm{kg})$ & $33.7 \pm 4.3$ & $33.6 \pm 4.8$ & 0.859 \\
Fracture side, L/R & $64 / 52$ & $60 / 34$ & 0.204 \\
Duration of surgery, min & $30.2 \pm 6.2$ & $44.7 \pm 9.4$ & $<0.001^{*}$ \\
Images taken during the operation & $6.5 \pm 1.1$ & $11.6 \pm 2.2$ & $<0.001^{*}$ \\
From injury to surgery (d) & $5.0 \pm 1.4$ & $5.3 \pm 1.4$ & 0.114 \\
\hline
\end{tabular}

EF External fixator, $K W$ Kirschner wire

Data shown as mean \pm SD or $\mathrm{N}(\%)$

${ }^{*}<0.01$

the treatment of unstable MDJ fractures in children [4]. However, the iatrogenic damage to physis cannot be overlooked, and if the KW diameter is too small, the stability of reduction is questionable. Therefore, the authors recommended additional stabilization.

In our study, the operative time was shorter in the EF group than the KW group. In order to provide reliable stability, the KW advancement should remain at an acute angle between the KW trajectory and the skin. However, cortical penetration is quite challenging in this technique. Kapandji technique has been reported in the treatment of DDRF in children [23], but it is not the mainstream choice and not adopted in our institute. In clinical practice, multiple KWs placement might be required for an adequate reduction and stable construct; however, it might increase the risk of iatrogenic injury [24]. In contrast, the threaded screw in the EF provides a "joystick" and is conducive to reduction. The placement of the Schanz screw under fluoroscopy is also relatively simple.

The purpose of surgical intervention is to reduce the risk of redisplacement following fracture reduction. The

Table 6 Follow-up data for children with isolated radial MDJ fracture in EF and KW group

\begin{tabular}{llll}
\hline Parameter & EF $(n=116)$ & KW $(n=94)$ & P Value \\
\hline Hardware removal, weeks & $6.5 \pm 1.1$ & $6.6 \pm 1.2$ & 0.677 \\
Pin tract infection (\%) & 10.3 & 11.7 & 0.756 \\
Tendon Irritation (\%) & 0 & 18.1 & $<0.001^{*}$ \\
Forearm pronation $\left(^{\circ}\right)$ & $87.2 \pm 1.7$ & $87.2 \pm 1.7$ & 0.991 \\
Forearm supination $\left(^{\circ}\right)$ & $87.6 \pm 1.7$ & $87.9 \pm 1.7$ & 0.155 \\
DASH score & $12.3 \pm 1.7$ & $12.7 \pm 1.7$ & 0.112 \\
Angulation $\left(^{\circ}\right)$ & $2.5 \pm 1.7$ & $3.6 \pm 2.2$ & $<0.001^{*}$ \\
Volar tilt $\left(^{\circ}\right)$ & $6.7 \pm 1.1$ & $0.9 \pm 1.5$ & $<0.001^{*}$ \\
\hline
\end{tabular}

Data shown as mean \pm SD or $\mathrm{N}(\%)$

Angulation $=$ angulation on frontal plane

$* 0.01$ 
redisplacement in both the groups was considerably low, and no patient in our study required re-operation. The EF group showed better radiographic results in angulation on AP view and volar tilting, possibly due to better stability in EF than KW.

Our patients were divided into two subgroups as per the presence or absence of the ulna fracture. In patients with both-bone fractures of the forearm, the operative time was relatively longer. However, ulna was not routinely fixated in our case series; some surgeon still prefers to fixate the ulna for better stability.

A long-arm or short-arm slab was routinely applied after the surgery for 3-4 weeks. After the radiograph showing the evidence of callus formation, the slab was removed. However, if the patient was not compliant, prolonged use of cast was mandatory. After the removal of hardware, a short-arm brace was used for 3-4 weeks for every patient to reduce the risk of refracture, which might be the reason for the low rate of refracture in our study. Besides, sports activities were not allowed until full consolidation of the fracture on the radiographs.

Pin tract infection (PTI) was reported to be a common complication in the EF and KW $[25,26]$, however, all PTI resolved uneventfully with oral antibiotics. The incidence of tendon irritation was higher in the KW because the procedure was performed in percutaneous fashion, whereas the EF was performed using a small incision exposing the bone.

Despite an adequate sample size, several limitations exist in this study. Firstly, other fixation techniques, including ESIN and plate, were not included. Secondly, the number of X-rays exposure was recorded, yet the actual radiation dosage could not be meticulously measured and recorded. Thirdly, the cost-effect analysis was not performed in this study.

\section{Conclusion}

The EF was superior to KW in the treatment of radial MDJ fractures in adolescents.

The EF displayed shorter duration of surgery, less tendon irritation, and better radiographic outcomes than the KW. However, the cost-effect analysis remains to be investigated, because the EF is more expensive than KW.

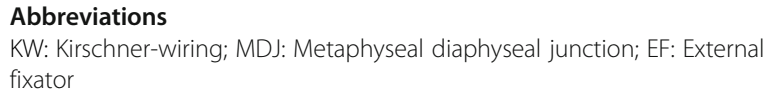

Acknowledgements

Not applicable.

\section{Authors' contributions}

$\mathrm{PH}^{*}$ is in charge of the main idea and is the guarantor of integrity of the entire clinical study; $J \mathrm{~L}$ and $\mathrm{RHZ}$ are in charge of the study concepts, design, manuscript preparation and editing; $\mathrm{PH}$ and SR are in charge of the language polishing and the grammar revision; RKL and XT is in charge of the collection of the study data. The authors read and approved the final manuscript.

Funding

None.

\section{Availability of data and materials}

The data sets supporting the conclusion of this article are included within the article. Upon request, raw data can be provided by the corresponding author.

Ethics approval and consent to participate

Not applicable.

\section{Consent for publication}

Written consents were obtained from the patients for publication of this paper.

\section{Competing interests}

The authors declare that they have no competing interests.

\section{Author details}

${ }^{1}$ Department of Orthopaedic Surgery, Union Hospital, Tongji Medical College, Huazhong University of Science and Technology, Wuhan 430022, China.

${ }^{2}$ Department of Orthopaedics and Trauma Surgery, National Trauma Center, National Academy of Medical Sciences, Kathmandu, Nepal. ${ }^{3}$ First School of Clinical Medicine, Tongji Medical College, Huazhong University of Science and Technology, Wuhan, China.

Received: 15 February 2020 Accepted: 4 June 2020

Published online: 09 June 2020

References

1. Cui $X$, Liang $L$, Wei $X$, et al. The efficacy, safety, and cost benefits of splints for fractures of the distal radius in children: a systematic review and metaanalysis protocol. Medicine (Baltimore). 2019;98(31):e16562.

2. Wendling-Keim DS, Wieser B, Dietz HG. Closed reduction and immobilization of displaced distal radial fractures. Method of choice for the treatment of children? Eur J Trauma Emerg Surg. 2015;41(4):421-8.

3. Handoll HH, Elliott J, Iheozor-Ejiofor Z, Hunter J, Karantana A. Interventions for treating wrist fractures in children. Cochrane Database Syst Rev. 2018; 12(12):CD012470 Published 2018 Dec 19.

4. Lieber J, Schmid E, Schmittenbecher PP. Unstable diametaphyseal forearm fractures: transepiphyseal intramedullary Kirschner-wire fixation as a treatment option in children. Eur J Pediatr Surg. 2010;20(6):395-8.

5. Zimmermann R, Gschwentner M, Pechlaner S, et al. Remodeling capacity and functional outcome of palmarly versus dorsally displaced pediatric radius fractures in the distal one-third. Arch Orthop Trauma Surg. 2004; 124(1):42-8.

6. Van der Reis WL, Otsuka NY, Moroz $\mathrm{P}$, et al. Intramedullary nailing versus plate fixation for unstable forearm fractures in children. J Pediatr Orthop. 1998:18:9-13.

7. Lieber J, Joeris A, Knorr P, et al. ESIN in forearm fractures: clear indications, often used, but some avoidable complications. Eur J Trauma. 2005;31:3-11.

8. Mengmeng D, Han J. Antegrade elastic stable intramedullary nail fixation for paediatric distal radius diaphyseal metaphyseal junction fracture: a new operative approach. Injury. 2019;50:598-601.

9. Noonan KJ, Price CT. Forearm and distal radius fractures in children. J Am Acad Orthop Surg. 1998:6:146-56.

10. De Smet L. The DASH questionnaire and score in the evaluation of hand and wrist disorders. Acta Orthop Belg. 2008;74:575-81.

11. Helber MU, Ulrich C. External fixation in forearm shaft fractures. Injury. 2000; 31(1):45-7.

12. Weinberg AM, Reilman $H$, Lampert $C$, et al. Experience with external fixation in treatment of shaft fractures in childhood. Unfallchirurg. 1994;97:107-13.

13. Gradl G, Gradl G, Wendt M, Mittlmeier T, Kundt G, Jupiter JB. Non-bridging external fixation employing multiplanar K-wires versus volar locked plating for dorsally displaced fractures of the distal radius. Arch Orthop Trauma Surg. 2013;133(5):595-602.

14. Bednar DA, Al-Harran H. Nonbridging external fixation for fractures of the distal radius. Can J Surg. 2004;47(6):426-30. 
15. Eichenbaum MD, Shin EK. Non-bridging external fixation of distal radius fractures. Hand Clin. 2010;26(3):381-vii.

16. Dwyer CL, Crosby NE, Cooney T, Seeds W, Lubahn JD. Treating unstable distal radius fractures with a nonspanning external fixation device: comparison with volar locking plates in historical control group. Am J Orthop (Belle Mead NJ). 2017;46(5):E344-52.

17. Korobeinikov A, Popkov D. Use of external fixation for juxta-articular fractures in children. Injury. 2019;50(Suppl 1):S87-94.

18. Yamako G, Ishii Y, Matsuda Y, Noguchi H, Hara T. Biomechanical characteristics of non-bridging external fixators for distal radius fractures. J Hand Surg Am. 2008;33(3):322-6.

19. Khandekar S, Tolessa $\mathrm{E}$, Jones $\mathrm{S}$. Displaced distal end radius fractures in children treated with Kirschner wires - a systematic review. Acta Orthop Belg. 2016;82(4):681-9.

20. Rai P, Haque A, Abraham A. A systematic review of displaced paediatric distal radius fracture management: plaster cast versus Kirschner wiring. J Clin Orthop Trauma. 2020;11(2):275-80.

21. Ramoutar DN, Shivji FS, Rodrigues JN, Hunter JB. The outcomes of displaced paediatric distal radius fractures treated with percutaneous Kirschner wire fixation: a review of 248 cases. Eur J Orthop Surg Traumatol. 2015;25(3):471-6.

22. Sengab A, Krijnen P, Schipper IB. Displaced distal radius fractures in children, cast alone vs additional K-wire fixation: a meta-analysis. Eur J Trauma Emerg Surg. 2019;45(6):1003-11.

23. Valisena S, Gonzalez JG, Voumard NM, et al. Treatment of paediatric unstable displaced distal radius fractures using Kapandji technique: a case series. Eur J Orthop Surg Traumatol. 2019;29(2):413-20.

24. Muratli HH, Yagmurlu MF, Yüksel HY, et al. Treatment of childhood unstable radius distal methaphysis fractures with closed reduction and percutaneous Kirschner wires. Acta Orthop Traumatol Turc. 2002;36:52-7.

25. Karantana A, Handoll HH, Sabouni A. Percutaneous pinning for treating distal radial fractures in adults. Cochrane Database Syst Rev. 2020;2(2): CD006080 Published 2020 Feb 7.

26. Yanagisawa $Y$, Ito A, Hara $Y$, et al. Initial clinical trial of pins coated with fibroblast growth factor-2-apatite composite layer in external fixation of distal radius fractures. J Orthop. 2018;16(1):69-73 Published 2018 Dec 20.

\section{Publisher's Note}

Springer Nature remains neutral with regard to jurisdictional claims in published maps and institutional affiliations.

Ready to submit your research? Choose BMC and benefit from:

- fast, convenient online submission

- thorough peer review by experienced researchers in your field

- rapid publication on acceptance

- support for research data, including large and complex data types

- gold Open Access which fosters wider collaboration and increased citations

- maximum visibility for your research: over $100 \mathrm{M}$ website views per year

At $\mathrm{BMC}$, research is always in progress.

Learn more biomedcentral.com/submissions 